\title{
Uncertainty of Deardorff's soil moisture model based on continuous TDR measurements for sandy loam soil
}

\author{
Andrzej Brandyk $^{1 *}$, Adam Kiczko ${ }^{2}$, Grzegorz Majewski $^{3}$, Małgorzata Kleniewska ${ }^{3}$, Marcin Krukowski ${ }^{2}$ \\ ${ }^{1}$ Water Center Laboratory, Faculty of Civil and Environmental Engineering, Warsaw University of Life Sciences WULS-SGGW, 166 \\ Nowoursynowska St., 02-776 Warszawa, Poland. \\ 2 Department of Hydraulics, Faculty of Civil and Environmental Engineering, Warsaw University of Life Sciences, 166 Nowoursynowska \\ St., 02-776 Warszawa, Poland. \\ ${ }^{3}$ Department of Meteorology and Climatology, Faculty of Civil and Environmental Engineering, Warsaw University of Life Sciences, 166 \\ Nowoursynowska St., 02-776 Warszawa, Poland. \\ * Corresponding author. Tel.: +48 225935377. E-mail: andrzej_brandyk@sggw.pl
}

\begin{abstract}
Knowledge on soil moisture is indispensable for a range of hydrological models, since it exerts a considerable influence on runoff conditions. Proper tools are nowadays applied in order to gain in-sight into soil moisture status, especially of uppermost soil layers, which are prone to weather changes and land use practices. In order to establish relationships between meteorological conditions and topsoil moisture, a simple model would be required, characterized by low computational effort, simple structure and low number of identified and calibrated parameters. We demonstrated, that existing model for shallow soils, considering mass exchange between two layers ( the upper and the lower), as well as with the atmosphere and subsoil, worked well for sandy loam with deep ground water table in Warsaw conurbation. GLUE (Generalized Likelihood Uncertainty Estimation) linked with GSA (Global Sensitivity Analysis) provided for final determination of parameter values and model confidence ranges. Including the uncertainty in a model structure, caused that the median soil moisture solution of the GLUE was shifted from the one optimal in deterministic sense. From the point of view of practical model application, the main shortcoming were the underestimated water exchange rates between the lower soil layer (ranging from the depth of 0.1 to $0.2 \mathrm{~m}$ below ground level) and subsoil. General model quality was found to be satisfactory and promising for its utilization for establishing measures to regain retention in urbanized conditions.
\end{abstract}

Keywords: Soil moisture; Modelling; Parameters uncertainty; GSA-GLUE analysis.

\section{INTRODUCTION}

Mathematical models are explicitly used to predict soil moisture on different scales, since it is the moisture itself that tends to be an important indicator of water runoff in rural or urbanized catchments (Berezowski et al., 2012). Detailed knowledge of the state of soil moisture (spatial and temporal) is essential also for a wide range of applications in agriculture and water management. Rootzone soil moisture can be used as an index in the prediction of crop yields and in early warning systems (for flood or drought). The important influence of soil moisture on weather and climate has been demonstrated for instance by (Deardorff, 1977; Namias, 1959; Reed, 1925). It has been proved to control the partitioning between the sensible and latent heat fluxes, and consequently influences the temperature of the surface and the lower atmosphere (Delworth, and Manabe, 1988). Further feedback may be visible through changed cloudiness, relative humidity, altered surface albedo, roughness and upper-level atmospheric circulation. For those reasons, soil moisture has gained importance in a multitude of hydrological models (Walker et al., 2001).

Comprehensive studies on modelling techniques for soil temperature and moisture were developed by Deardorff (1977). On the other hand, insight into moisture profiles was attempted from surface measurements, and given in: (Arya et al., 1983; Camillo and Schmugge, 1983; Entekhabi et al., 1994; Jackson, 1980). Independent of the applied technique, the gained knowledge on the soil wetness status is indispensable for catchment runoff modelling, that usually requires complex models with spatially distributed parameters, having prescribed uncertainty ranges (Marcinkowski et al., 2013; Sikorska et al., 2012). Among those parameters, the soil water content is one of the most important to trigger surface runoff (Brandyk and Majewski, 2013; Chormański, 2012; Deardorff, 1977).

Nonetheless, the majority of contemporary hydrological models, incorporating soil moisture significance for overall catchment hydrology, require computational effort, detailed data acquisition, diverse and rather complicated calibration procedures. For these reasons, a simple, analytical model of uppermost soil layers moisture seems to be of broad importance. It ought to be characterized by simplified application procedure, low number of parameters to be identified and calibrated, and, if possible, more insignificant computational needs. The final model result is only the soil water content, however, all complex procedures related with data management and processing in a GIS system, for instance, are avoided.

Since in situ soil moisture observations are often limited due to equipment and time availability, model-simulated soil moisture products often serve as alternatives (i.e., for providing initial conditions and/or inputs) for a range of weather and climate models, crop models, ecosystem models, agricultural drought monitoring, and, as it was already stressed, flood monitoring. Soil moisture data are nowadays retrieved as well from satellite-based remote sensing, such as AMSR-E (Advanced Microwave Scanning Radiometer for the Earth Observing System; Reichle et. al., 2011), ASCAT (Advanced Scatterometer; Wagner et al., 1999) and SMOS (Soil Moisture and Ocean Salinity; Kerr et al., 2010), and offer potential, however, they are generally useable only in the upper few 
centimetres over sparsely vegetated area for microwave sensors, even if efforts are being made to extrapolate these measurements to the root zone (Gao et al., 2003; Reichle et al., 2011). In such situation, soil moisture data acquisition requires choosing and applying proper model for soil hydrology, with a necessity to identify the key processes that are active in the catchment under consideration and to ensure that they are satisfactorily represented by the model (Beven and Kirkby, 1979; Boughton, 1983; Hughes, 1994).

We hypothesized that simple analytical flow model of shallow, two-layer soil (depth equals $20 \mathrm{~cm}$ ), considering exchange between layers, the atmosphere and subsoil, reproduces satisfactorily temporal changes of soil moisture as dependent on existing meteorological conditions. The main novelty of the presented study is that we conditioned it on very accurate observations. The meteorological inputs and soil moisture were measured in a close distance, to exclude potential small scale differences in weather conditions. Furthermore, the soil moisture data were collected taking the advantage of the Time Domain Reflectometry technique, providing detailed and almost continuous information on system dynamics.

We also stressed, that the model used herein would establish relationships between the weather and soil moisture status after the parameter identification, for which we employed GSAGLUE (Global Sensitivity Analysis, Generalized Likelihood Uncertainty Estimation) framework (Beven and Binley, 1992). It is based on the probabilistic representation of the parameters' uncertainty, fulfilled with model's sensitivity analysis. The link between GSA and GLUE was established using likelihood measures, elaborated within the GLUE method, as a model output for the sensitivity analysis. As a result it was possible to perform that analysis without strong assumptions concerning parameters variation, leading to final adoption of model confidence bands. We found no previous attempts of applying linked GLUE-GSA analysis for soil moisture time series data.

\section{MATERIALS AND METHODS}

The research was performed for a loamy soil in the southern district of Warsaw (Ursynów district) within the compounds of Warsaw University of Life Sciences. That area is characterized by high degree of anthropopressure. There is a high coverage by impervious areas e.g. the presence of large area of housings, sidewalks, car parks and main streets, which contribute to quick generation of overland flow. However, in unpaved areas, such as parks and open green surface, water storage in the soil seems to be important so as to increase water retention of urbanized areas of Warsaw city.

Geological setting, involved generally sandy loams up to 1.9 $\mathrm{m}$ depth (Matusiewicz, 2013; Wienclaw, 1998), underlain by sandy clay of thickness higher than $10 \mathrm{~m}$, with deep ground water table - about $11 \mathrm{~m}$ below land surface. It was found, that soil layers to the depth of $0.2 \mathrm{~m}$, for which moisture was measured by TDR probes, contained $65 \%$ of sand fraction (diameter $2-0.05 \mathrm{~mm}$, including: $24 \%$ of coarse sand (1-0.5 $\mathrm{mm}), 16 \%$ of medium sand $(0.5-0.25 \mathrm{~mm}), 13 \%$ of fine sand $(0.25-0.1 \mathrm{~mm})$ and $12 \%$ of very fine sand $(0.1-0.05 \mathrm{~mm})$. Silt fraction totalled $24 \%$ (diam. $0.05-0.002 \mathrm{~mm}$ ) with $11 \%$ of coarse silt $(0.05-0.02 \mathrm{~mm})$ and $13 \%$ of fine silt $(0.02-0.002$ $\mathrm{mm}$.) and finally clay fraction (diam. $<0.002 \mathrm{~mm}$ ), totalling $11 \%$ (Szejba et. al., 2003). Grain size classes were adopted from USDA (Soil Survey Division Staff, 1993), and according to those, the presence of sandy loam in the uppermost soil layers is confirmed. For grain distribution analyses we used laboratory sieves with diameters from $1 \mathrm{~mm}$ to $0.05 \mathrm{~mm}$. Silt and clay fractions were determined with a hydrometer ("Procedures for soil analysis", 1995). Next, we determined the percentage of organic matter and bulk soil density that enabled to use equations proposed by Wösten et.al. (1999) in order to calculate basic parameters for van Genuchten (1980) equation of retention curve in which residual water content $w_{r}$ was $0.000 \mathrm{~m}^{3} \mathrm{~m}^{-3}$, saturated water content $w_{s}$ was $0.404 \mathrm{~m}^{3} \mathrm{~m}^{-3}$, fitting parameters were $\alpha 0.070 \mathrm{~cm}^{-1}$ and $n 1.364$.

All soil and weather data were collected within the campus of Warsaw University of Life Sciences. The meteorological data used in this study were sourced from the WULS Ursynów meteorological station $\left(\lambda_{\mathrm{E}} 21^{\circ} 02^{\prime} 52^{\prime}, \varphi_{\mathrm{N}} 52^{\circ} 09^{\prime} 38^{\prime \prime}, 102.5 \mathrm{~m}\right.$ a.s.1.), operated by the WULS Division of Meteorology and Climatology. Air temperature and relative humidity was measured using thermohygrometer sensor (Vaisala :QMH102, temperature range: $-40 ;+60^{\circ} \mathrm{C}$, temperature accuracy $< \pm 0,3{ }^{\circ} \mathrm{C}$, relative humidity range: $0-100 \%$, rel. humidity accuracy $\pm 2 \%$, ( 0 to $90 \% \mathrm{RH})$ and $\pm 3 \%$, (90 to $100 \% \mathrm{RH})$ ) located at $2 \mathrm{~m}$ above the active surface, and wind speed was measured at $4 \mathrm{~m}$ height by sonic sensor (Vaisala, WS425 - B2A1B, range: 0 - 56 $\mathrm{m} / \mathrm{s}$, accuracy: $\pm 0.135 \mathrm{~m} / \mathrm{s}$ or $\pm 3 \%$ of the range, wind direction range: $0-360^{\circ}$, accuracy $\pm 2^{\circ}$ for wind speed $>2 \mathrm{~m} / \mathrm{s}$ ). Daily precipitation totals were used as input data for soil moisture model, whereas air temperature, relative humidity and wind speed, were used to calculate potential evapotranspiration according to FAO procedure (Allen et al., 1998) on hourly time step basis by Penman-Monteith equation:

$$
E_{p}=K \frac{0.408 \Delta\left(R_{n}-G\right)+\gamma \frac{37}{T_{h r}+273} u_{2}\left(e^{0}\left(T_{h r}\right)-e_{a}\right)}{\Delta+\gamma\left(1+0.34 u_{2}\right)}
$$

where: $E_{p}$ stands for reference evapotranspiration, $R_{n}$ is a net radiation at the grass surface, calculated according to FAO procedure, $G$ represents soil heat flux density calculated according to FAO procedure, $T_{h r}$ is a mean hourly air temperature, $u_{2}$ is an average hourly wind speed, $e^{0}\left(T_{h r}\right)$ is a saturation vapour pressure at air temperature $T_{h r}, e_{a}$ stands for average hourly actual vapour pressure, $\Delta$ is slope of vapour pressure curve, $\gamma$ denotes a psychrometric constant and $K$ is a unit conversion factor (note that Penman-Monteith equation is not given in the International System of Units). Hourly evapotranspiration data were then taken to calculate daily sum of evapotranspiration.

Soil moisture and temperature were measured with TDR probes at two soil depths: 10 and $20 \mathrm{~cm}$ at the above mentioned meteorological station, where the land surface was covered by standard, mown grass of $10 \mathrm{~cm}$ height. All data were recorded by data logger manufactured by the Institute of Agrophysics of the Polish Academy of Sciences (PAS), Lublin, Poland, and were characterized by non-invasive and fully automated measurements. The measurements involved permanent recording of the propagation step impulse of energy into a soil system and the subsequent observation of the energy reflected by the system within a test time equal to $5 \mathrm{~s}$. The impulse frequency was $\sin ^{2}$ - like needle pulse of 200 ps rise time and the probe length equal to $30 \mathrm{~cm}$ (cable length equal to $6 \mathrm{~m}$ ). The sensor consisted of two $100 \mathrm{~mm}$ long, parallel, stainless rods, having $2 \mathrm{~mm}$ in the diameter and separated by $16 \mathrm{~mm}$. TDR measured the dielectric permittivity of the soil, which is known to be strongly related to soil moisture content because of the strong contrast between the dielectric permittivity of water and that of the other soil constituents. Empirical and 
semitheoretical models are available to relate dielectric permittivity and soil moisture content (Roth et al., 1990; Topp et al., 1980). In the applied TDR method we used the equation developed by Malicki for mineral soils (Malicki et al., 1996). That equation, elaborated for the area of Poland, relates volumetric soil water content with the measured dielectric constant and soil bulk density, and is written in the following form:

$$
w=\frac{\sqrt{K_{a}}-0.819-0.168 \rho_{b}-0.159 \rho_{b}^{2}}{7.17+1.18 \rho_{b}}
$$

where $K_{a}$ stands for dielectric constant and $\rho_{b}$ for soil bulk density.

The application of Equation (2) in PAS - TDR measuring system enabled to read water content directly from the data logger. Moisture measurements (volumetric water content) were performed in the range of 0 to $100 \%$ by the above mentioned equipment with the absolute error of $\pm 2 \%$ and resolution of readings equal to $0.1 \%$. Measurements, previously performed with PAS TDR, were compared to gravimetric method for sixty soils all over the area of Poland, so as to prove the reliability of the applied TDR probes for a range of soil densities (Boczoń, 2004). Determination coefficient for the compared variables was equal to 0.98 and standard deviation of moisture content reached slightly higher value than nominal one, equal to 0.028 . The TDR sampling interval was equal to 10 minutes, and the sampling was continued throughout the vegetation period of 2011 (from 1 April, 2011 till 30 September 2011). Similar to weather data, averaged daily values of soil moisture were then used for analyses.

\section{Soil moisture modelling}

To trace the relationship between meteorological parameters and soil moisture we have applied the quasi physical model, based on the concept presented by Deardorff (1977). The variability of a soil moisture can be described as a processes of a mass exchange between atmosphere and two soil layers: upper and lower. The first, the surface layer, represents the transitional zone where the soil moisture content is strongly affected by diurnal variations. It is relatively thin, up to $10 \mathrm{~cm}$. In the second layer the variability is significantly lower. The Deardorff's model involves then only two time depended variables: the soil-surface moisture content - for a first layer and the bulk soil content for the second one:

$$
\begin{aligned}
& \frac{\partial w_{1}}{\partial t}=-C_{1} \frac{E_{g}-P}{h_{1}}-C_{2} \frac{w_{1}-w_{2}}{\tau}, 0<w_{1} \leq w_{\max } \\
& \frac{\partial w_{2}}{\partial t}=-\frac{E_{g}-P}{h_{2}}-\mu w_{2}, 0<w_{2} \leq w_{\max }
\end{aligned}
$$

where $w_{1}, w_{2}$ denotes the volumetric water content at upper and lower layer, respectively, $h_{1}$ and $h_{2}$ represent thickness of layers, $P$ is a precipitation intensity, $\tau$ is a diurnal time period (1 day expressed in seconds), $C_{1}, C_{2}$ are dimensionless proportionality factors, $E_{g}$ the bare-soil evaporation, $\mu$ is a constant used to describe the moisture transport below a lower layer and $w_{\max }$ is the soil field capacity. It has to be noted that variables in Equations (3), contrary to the original Deardorff's notation, were divided by the liquid density (e.g. $P$ is given here in $\mathrm{m} / \mathrm{s}$ instead of $\mathrm{kg} / \mathrm{m}^{2} \mathrm{~s}$ ). The $C_{1}$ and $C_{2}$ parameter values depend on the soil moisture and texture, the functional forms were given by Noilhan and Planton (1989). In the Deardorff approach the $C_{2}$ parameter is a constant and $C_{1}$ has a form of a piecewise function of effective saturation $\left(C_{1}=f\left(w_{l} / w_{\max }\right)\right.$. The present model follows the Deardorff's formulation, however we adopted different form of the function for $C_{1}$. Still its value is parametrized against effective saturation, however in the form of a power function of a single parameter:

$C_{1}=\left(\frac{w_{1}}{w_{\max }}\right)^{m}$

where $\mathrm{m}$ stands for the model parameter. The modification was imposed to reduce the total number of parameters, as a piecewise relationship requires two more. For $m<0$, the proposed form maintains the decreasing character of the $C_{1}$ factor with saturation. The exponential form also provides better agreement with an experimental set given by Noilhan and Planton (1989). With the Equation (4) it is possible to reproduce the dependency given with the data points for all three soil classes: sand, loam and clay, with a coefficient of a linear correlation higher than 0.95 .

The moisture transport was not included in the Deardorff's model as it was limited to a time period of only few weeks. Here, to extend the time scale we added the sink term to Equations (3) that allow taking an account of the moisture transport outside the model's domain. The term takes a form of linear relationship, used in the similar studies, i.e.: (Huang et al., 1996). The bare-soil evaporation rate $\left(E_{g}\right)$ was related to the potential evaporation $\left(E_{p}\right)$ with the following relationship (Deardorff, 1977):

$$
E_{g}= \begin{cases}\left(\frac{w_{1}}{w_{\text {sat }}}\right) E_{p} & w_{1}<w_{\text {sat }} \\ E_{p} & w_{1} \geq w_{\text {sat }}\end{cases}
$$

where $w_{\text {sat }} \approx 0.75 w_{\text {max }}$

Equations (3) were solved using the explicit Runge-Kutta method, provided by the ode 23 solver, being a part of the Matlab computing software (Shampine and Reichelt, 1997). The variables: $m, C_{2}, \mu$ and $w_{\max }$ were treated as model parameters.

\section{Identification of model parameters}

In any modelling assignment the parameter identification is a challenging task. Often it is possible to relate parameter values with certain system properties. The example could be the values of $C_{1}$ or $C_{2}$ for which the dependency on soil type and moisture was given by Noilhan and Planton (1989). However, such approach requires significantly more information concerning the modelled system, being unavailable in many cases. The alternative is to look for parameters that brings model output possible close to measured values. This is the approach being utilized in the present study. The parameter identification is considered here in a form of an inverse problem, where the goal is to find such parameter ensemble that provides the satisfactory agreement between the model and the real system. 
To identify model parameter a probabilistic framework of the GSA-GLUE (Global Sensitivity Analysis with Generalized Likelihood Uncertainty Estimation, Ratto et al., 2001) was adopted. It is a combination of the model uncertainty analysis with respect to parameters with the estimation of a model sensitivity of these uncertain parameters.

The basic assumption of this approach comes from the statement made by Beven and Binley (1992) that because of simplifications and errors in a model structure, errors in observations, it is improper to expect that only one parameter set represents true parameter values. The parameter identification should then lie in estimation of their probability distribution, reflecting the uncertainty of predictions. In this light, the existence of many parameter sets that are considered as satisfactory, is expected.

In the GLUE approach the parameter identification is performed according to the Bayes formula:

$M(x / w)=\frac{M(x) M(w / x)}{M(w)}$

where $x$ stands for a parameter vector, here $x=\left(m C_{2} \mu w_{\max }\right)$, w observed soil moisture content, $M(x)$ a priori parameter distribution, $M(w / x)$ likelihood function, $M(w)$ scaling factor and $M(x / w)$ a posteriori parameter distribution. In the GLUE methodology, its informal character, the choice of likelihood function depends on the modeller knowledge and it should reflect the expectations over a posteriori distribution properties. In the presented study we have chosen the following form (Romanowicz and Beven, 2006):

$$
M(w / x)=p \exp \left(\frac{-r_{m}^{2}(x)}{\kappa \sigma^{2}}\right)
$$

where $r_{m}(x)$ denotes a model mean residua, $\sigma^{2}$ a mean variance of the model residua, $\kappa$ a shape factor used to control a variance of function values, $p$ a scaling factor, such that $\sum M(w / x)=1$. This Gauss-shaped function reaches maximum for $r(x)=0$ and approaches zero when residuals increase. Parameter sets for which solution strongly differs from the observed system output, with high residuals ranked with likelihood value close to zero. The distinction between behavioural and nonbehavioural realizations used in the original GLUE formulation is done here indirectly using formula 7 by adjusting the shape factor $\kappa$. (Kiczko et al., 2013; Romanowicz and Beven, 2006).

Table 1. The parameter ranges used in the uniform a priori distribution.

\begin{tabular}{lcccc}
\hline & $m$ & $C_{2}$ & $\mu$ & $w_{\max }$ \\
& {$[-]$} & {$[-]$} & {$[-]$} & {$[-]$} \\
\hline Lower band & -5 & 0 & 0 & 0.24 \\
Upper band & 0 & 14 & $10^{-7}$ & 0.42 \\
\hline
\end{tabular}

The use of likelihood function allows reducing the significance of assumptions concerning parameters distribution. As in a common situation, the variability of parameters is unknown, mostly an uniform distribution is used. It is also a case in this study. The parameter ranges were adopted to reflect their physical interpretation. The $m$ parameter was sampled in bands in which it is possible using formula 4 reproduce the empirical relationship of $C_{2}$ on soil moisture as given by Noilhan and Planton (1989). Same applies to the constant value of $C_{1}$.Field capacity of a soil $w_{\max }$ was assumed to fall between 0.24 and 0.42 . The ranges of the $\mu$ coefficients were chosen by trial and errors, to obtain sufficiently diverse parameter ensemble. The information concerning parameter distribution is set up in Table 1.

The sensitivity analysis allows to investigate the significance of certain parameters on model performance. In our study we take advantages of the Global Sensitivity Analysis (Archer et al., 1997), which is suitable i.e. for non-monotonic models. The method is based on a variance decomposition in the sum of top marginal variance and a bottom marginal variance:

$$
V(Y(x))=V[E(Y(x / u))]+E[V(Y(x / u))]
$$

where $Y$ denotes a model output, $u$ a group of parameters. The first term describes the reduction of the output variance when the set $u$ becomes fully known and the second one is the expected value of the variance in the case all parameters, except $u$, are known (Ratto et al., 2001). It enables to trace an effect of an input variance of a certain parameter or combinations of parameters.

The sensitivity of the model is assessed with the use of two measures, the First Order Sensitivity Index $S_{i}$ and the Total Sensitivity Index $S_{T i}$, defined as follows:

$$
S_{i}=\frac{V\left[E\left(Y\left(x / u_{i}=x_{i}^{*}\right)\right)\right]}{V(Y)}
$$

$S_{T i}=\frac{E\left[V\left(Y\left(x / u_{-i}=x_{-i}^{*}\right)\right)\right]}{V(Y)}$

The First Order Sensitivity gives an account of amount of output variation reduction in case when parameter $x_{i}$ is known and remains fixed. The Total Sensitivity Index is introduced to investigate significance of interactions between parameters and gives an idea about all the interactions involving parameter $x_{i}$.

The link between GSA and GLUE is established using likelihood measures, elaborated within the GLUE method, as a model output for the sensitivity analysis. As a result it is possible to perform the analysis in a case when there are no strong assumptions concerning parameters variation. Moreover, as both methods are based on the Monte Carlo sampling technique, it is possible to perform the sensitivity and uncertainty analysis for the same parameter ensemble, with restriction that it maintains a structure required for GSA.

The number of Monte Carlo runs of the model was 10,000. The shape factor $\kappa$ of the likelihood function was adjusted manually to enclose observed moisture, where it was possible, within $95 \%$ confidence bands of the model. The bands were calculated on the basis of the a posteriori distribution of the modelled moisture.

The probabilistic solution is compared with one obtained on the deterministic grounds. It was elaborated using the same Monte Carlo sample as in the GSA-GLUE, from which a parameter set with the highest value of the likelihood function was chosen. 


\section{RESULTS AND DISCUSSION}

The modelled soil moisture is presented in Fig. 1, which also gives a comparison between the deterministic and probabilistic solutions. Including the uncertainty in a model structure causes that the median solution of the GLUE is shifted from the one optimal in deterministic sense. In Fig. 2 the parameter ensemble is set together with values of the likelihood measure in a form of dot plots. The simple graphical interpretation allows identifying the regions in a parameter space with the highest likelihood. The ensemble likelihood reaches its maximum for values of the parameter $m$ close at the bound of $-1, C_{2}$ heading to 14 and around $0.28-0.30$ for $w_{\max }$. In a case of a $\mu$ parameter which represents the sink term for the lower layer, the likelihood is increasing towards negative values. This is consistent with the observed bias for the lower layer, where measurements suggest higher water supply to this zone. The dependency of the likelihood function on certain parameters seen in dot-plots is also seen in the results of the sensitivity analysis, presented in Table 2 . The highest values of the first and total order sensitivity indexes were obtained for $C_{2}$ and $\mu$ parameters. Both parameters: $m$ and $w_{\max }$, have a relatively small direct impact with a low value of the first order sensitivity index, affect the model performance by interactions with other parameters, that can be seen in noticeable values of total sensitivity indexes.

In general, parameter values achieved by applying GSAGLUE algorithm, provided for a satisfactory quality of the model that linked meteorological conditions to topsoil moisture. However, for the validation period the model overestimated the water content in the second soil layer. The reason for this was the best fit of the zero value of $\mu$ parameter in the calibration period. That parameter stands for leakage rate from the second (lower) layer to subsoil. Most likely, the leakage was indeed

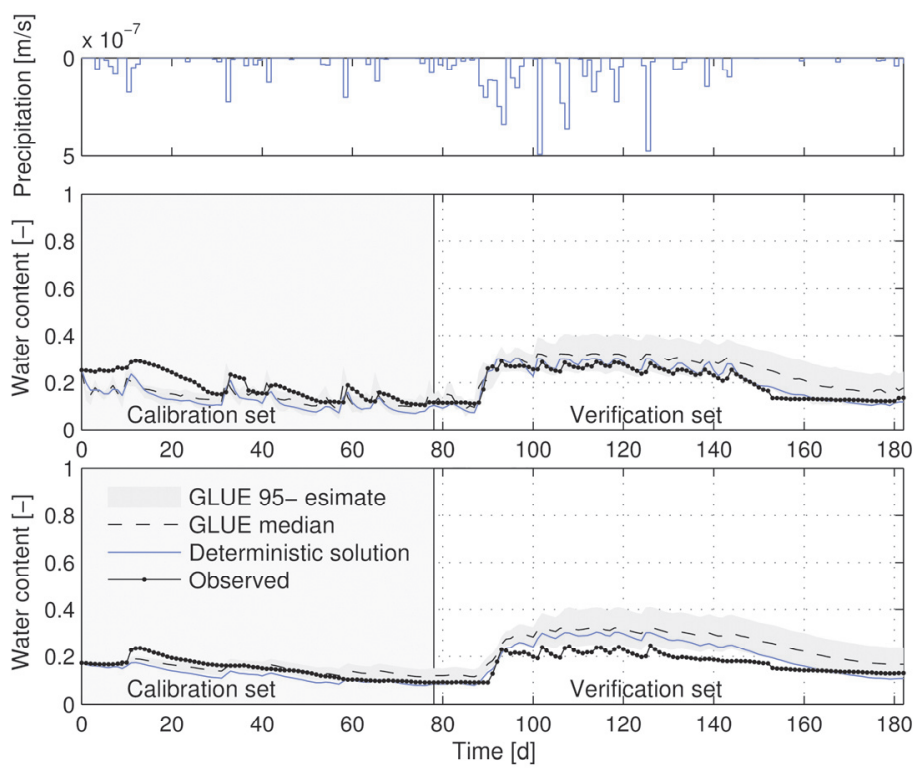

Fig. 1. The computed soil moisture content with $95 \%$ confidence bands; (a) - precipitation, (b) the first layer, (b) the second layer.
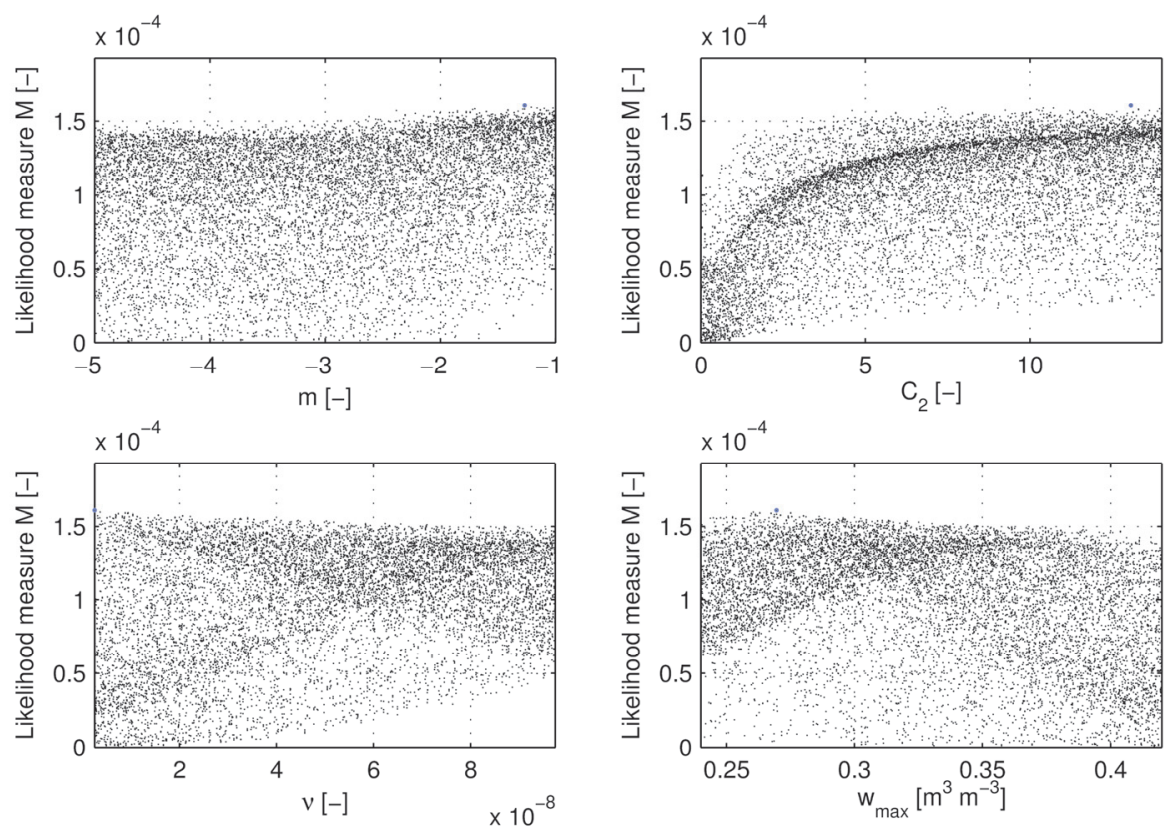

Fig. 2. The parameter ensemble in relation to likelihood measure. 
Table 2. The sensitivity indexes for model parameters.

\begin{tabular}{lccccc}
\hline & & $m$ & $C_{2}$ & $\mu$ & $w_{\max }$ \\
\hline First order sensitivity index $S_{i}$ & {$[-]$} & 0.019 & 0.358 & 0.148 & 0.099 \\
\hline Total sensitivity index $S_{T i}$ & {$[-]$} & 0.168 & 0.672 & 0.548 & 0.309 \\
\hline
\end{tabular}

equal to zero during the calibration period, whereas its' nonzero values appeared in the validation one. Such nonstationarity of the water transport could be justified by considerable recharge to soil profile after winter period e.g. upward seepage from perched water tables.

For the $m$ and $C_{2}$ the maximum values of the likelihood function was obtained at the boundaries of their physical ranges. It confirms that the model does not hold its physical interpretation and/or not all source and sink terms were included in the model structure.

\section{CONCLUSIONS}

The simple model of mass fluxes between two soil layers appeared to be sufficient in representing the dynamics of the soil moisture and provided a satisfactory agreement with measurements performed using TDR technique. The main difficulty arose from the grey-box nature of the model, with many relationships, defined in empirical terms using mostly unmeasurable parameters. The probabilistic framework of the GLUE technique applied here seems to be advantageous, as it enables the direct analysis of various parameter combinations, giving an insight into regions in the parameter space, where the value is the most likely. Moreover, results support the assumption underlying the GLUE concept, that for overparametrized models there might be many models or parameters sets that lead to a satisfactory representation of the true process and for which available constrains do not allow to limit the solution to optimal in a deterministic sense. Such conclusion can be drawn from the relationship between parameter values and the likelihood measure, but also from the sensitivity analysis. It revealed strong parameter interactions, where a direct effect of a single parameter is at least few times smaller comparing with join effects with other parameters.

Despite the overall satisfactory representation of the moisture dynamics by the model, the results for the lower soil layer are noticeable biased. This suggests that a sink term might be inappropriate, as the best fit was obtained when water flux below the second layer was set to zero $(\mu=0)$. The analysis revealed the significance of water exchange between upper and lower layer of the soil and suggested that this process might have a non-stationary character.

Acknowledgements. We acknowledge the technical support and the facilities provided by the Warsaw University of Life Sciences for field soil-water data collection. We also would like to thank the Water Centre Laboratory of WULS for providing software that has been used in this study to retrieve data from TDR probes.

\section{REFERENCES}

Allen, R.G., Pereira, L.S., Raes, D., Smith, M., 1998. Crop evapotranspiration-Guidelines for computing crop water requirements. FAO Irrigation and drainage, paper 56. FAO, Rome, 300(9): D05109.
Archer, G.E.B., Saltelli, A., Sobol, I.M., 1997. Sensitivity measures, ANOVA-like techniques and the use of bootstrap. J. Stat. Comput. Sim., 58, 2, 99-120.

Arya, L.M., Richter, J.C., Paris, J.F., 1983. Estimating profile water storage from surface zone soil moisture measurements under bare field conditions. Water Resources Research, 19, 2, 403-412.

Berezowski, T., Chormański, J., Batelaan, O., Canters, F., Van de Voorde, T., 2012. Impact of remotely sensed land-cover proportions on urban runoff prediction. Int. J. Appl. Earth Obs., 16, 54-65.

Beven, K.J., Kirkby, M.J., 1979. A physically based, variable contributing area model of basin hydrology/Un modèle à base physique de zone d'appel variable de l'hydrologie du bassin versant. Hydrolog. Sci. J., 24, 1, 43-69.

Beven, K., Binley, A., 1992. The future of distributed models: model calibration and uncertainty prediction. Hydrol. Proces., 6, 3, 279-298.

Boczoń A., 2004. Water consumption by oaks in the moist forest habitat. Monograph of Water Management Committee of the Polish Academy of Sciences. Warsaw, 44-45. (In Polish.)

Boughton, W.C., 1983. A simple model for estimating the water yield of ungauged catchments. Civ. Eng. Trans., CE25, 83-88.

Brandyk, A., Majewski, G., 2013. Modeling of hydrological conditions for the restoration of Przemkowsko- Przecławskie Wetlands. Rocz. Ochr. Sr., 15, 1, 371-392.

Camillo, P., Schmugge, T.J., 1983. Estimating soil moisture storage in the root zone from surface measurements. Soil Sci., 135, 4, 245-264.

Chormański, J., 2012. Analysis of urbanization impact on changes in river discharge - a case study of the Biała River catchment. Studia Geotechnica et Mechanica, 34, 2, 19-32.

Deardorff, J.W., 1977. A parameterization of ground-surface moisture content for use in atmospheric prediction models, J. Appl. Meteorol. Clim., 16, 11, 1182-1185.

Delworth, T.L., Manabe, S., 1988. The influence of potential evaporation on the variabilities of simulated soil wetness and climate. J. Climate, 1, 5, 523-547.

Entekhabi, D., Nakamura, H., Njoku, E.G., 1994. Solving the inverse problem for soil moisture and temperature profiles by sequential assimilation of multifrequency remotely sensed observations. IEEE Trans. Geosci. Remote Sensing, $32,438-448$.

Gao, Z., Fan, X., Bian, L., 2003. An analytical solution to onedimensional thermal conduction-convection in soil. Soil Sci., 168, 2, 99-107.

Huang, J., van den Dool, H.M., Georgarakos, K.P., 1996. Analysis of model-calculated soil moisture over the United States (1931-1993) and applications to long-range temperature forecasts. J. Climate., 9, 6, 1350-1362.

Hughes, D.A., 1994. Soil moisture and runoff simulations using four catchment rainfall-runoff models. J. Hydrol., 158, 3, 381-404. 
Jackson, T.J., 1980. Profile soil moisture from surface measurements. Journal of the Irrigation and Drainage Division (ASCE), 106, 81-92.

Kerr, Y.H., Waldteufel, P., Wigneron, J.P., Delwart, S., Cabot, F., Boutin, J., Mecklenburg, S., 2010. The smos mission: New tool for monitoring key elements of the global water cycle. Proceedings of the IEEE, 98, 5, 666-687.

Kiczko, A., Romanowicz, R.J., Osuch, M., Karamuz, E., 2013. Maximizing the usefulness of flood risk assessment for the River Vistula in Warsaw. Nat. Hazard. Earth Sys. Sciences Discussions, 1, 2695-2730.

Malicki, M.; Plagge, R., Roth, C., 1996. Improving the calibration of dielectric TDR soil moisture determination taking into account the solid soil. Eur. J. Soil Sci., 47, 357-366.

Marcinkowski, P., Piniewski, M., Kardel, I., Giełczewski, M., Okruszko, T., 2013. Modeling of discharge, nitrate and phosphate loads from the Reda catchment to the Puck Lagoon using SWAT. Warsaw Univ. Life Sci. - SGGW Land Reclam., 45, 2, 125-141.

Matusiewicz, W., 2013. Foundation walls drying and dewatering of soil adjacent to the Ursyn Niemcewicz Palace. Sci. Rev. Eng. Env. Sci., 60, 208-221.

Namias, J., 1959. Recent seasonal interactions between North Pacific waters and the overlying atmospheric circulation. J. Geophys. Res., 64, 6, 631-646.

Noilhan, J., Planton, S., 1989. A simple parameterization of land surface processes for meteorological models. Mon. Weather Rev., 117, 536-549.

Publication "Procedures for soil analysis" 5th Edition 1995 and the ISO Standard 11277:1998.

Ratto, M., Tarantola, S., Saltelli, A., 2001. Sensitivity analysis in model calibration: GSA-GLUE approach. Comput. Phys. Commun., 136, 3, 212-224.

Reed, C.D., 1925. Monthly Forecasts by Correlation June, a Key Month. Mon. Weather Rev., 53, 6, 249-251.

Reichle, R.H., Koster, R.D., De Lannoy, G.J., Forman, B.A., Liu, Q., Mahanama, S.P., Touré, A., 2011. Assessment and enhancement of MERRA land surface hydrology estimates. J. Climate, 24, 24, 6322-6338.

Romanowicz, R.J., Beven, K.J., 2006. Comments on generalised likelihood uncertainty estimation. Reliab. Eng. Syst. Safe., 91, 10, 1315-1321.

Roth, K., Schulin, R., Flühler, H., Attinger, W., 1990. Calibration of time domain reflectometry for water content measurement using a composite dielectric approach. Water Resour. Res., 26, 10, 2267-2273.

Shampine, L.F., Reichelt, M.W., 1997. The matlab ode suite. SIAM J. Sci. Comput., 18, 1, 1-22.

Sikorska, A.E., Scheidegger, A., Banasik, K., Rieckermann, J., 2012. Bayesian uncertainty assessment of flood predictions in ungauged urban basins for conceptual rainfall-runoff models. Hydrol. Earth Syst. Sc., 16, 4, 1221-1236.

Soil Survey Division Staff, 1993. Soil Survey Manual. Soil Conservation Service. U.S. Department of Agriculture Handbook, 18.

Szejba, D., Gnatowski, T., Oleszczuk, R., 2003. Soil physical and hydraulic properties estimation for the drainage of WULS sport facilities WULS expertise, Warsaw, July pp. 15. (In Polish.)

Topp, G.C., Davis, J.L., Annan, A.P., 1980. Electromagnetic determination of soil water content: Measurements in coaxial transmission lines. Water Resour. Res., 16, 3, 574-582.

Wagner, W., Lemoine, G., Rott, H., 1999. A method for estimating soil moisture from ERS scatterometer and soil data. Remote Sens. Environ., 70, 2, 191-207.
Walker, J.P., Willgoose, G.R., Kalma, J.D., 2001. Onedimensional soil moisture profile retrieval by assimilation of near-surface measurements: A simplified soil moisture model and field application. J. Hydrometeorol., 2, 4, 356-373.

Wienclaw, E., 1998. Hydrogeological setting of the Ursynów Scarp. Sci. Rev. Eng. Env. Sci., 14, 51-64.

Wösten, J.H.M., Lilly, A., Nemes, A., Le Bas, C., 1999. Development and use of a database of hydraulic properties of European soils. Geoderma, 90, 169-185.

van Genuchten, M.T., 1980. A closed-form equation for predicting the hydraulic conductivity of unsaturated soils. Soil Sci. Soc. Amer. J., 44, 892-898.

\section{NOMENCLATURE}

\begin{tabular}{|c|c|}
\hline$C_{1}, C_{2}[-]$ & dimensionless proportionality factors \\
\hline$e^{0}[\mathrm{kPa}]$ & saturation vapour pressure \\
\hline$e_{a}[\mathrm{kPa}]$ & $\begin{array}{l}\text { average hourly actual vapour pres- } \\
\text { sure }\end{array}$ \\
\hline$E_{g}[\mathrm{~m} / \mathrm{s}]$ & bare-soil evaporation \\
\hline$E_{p}[\mathrm{~m} / \mathrm{s}]$ & reference evapotranspiration \\
\hline$G\left[\mathrm{MJ} \mathrm{m}^{-2}\right.$ hour $\left.^{-1}\right]$ & soil heat flux density \\
\hline$h_{1}[\mathrm{~m}]$ & thickness of an upper layer \\
\hline$h_{2}[\mathrm{~m}]$ & thickness of an lower layer \\
\hline$K_{a}[-]$ & dielectric constant \\
\hline$m[-]$ & $\begin{array}{l}\text { parameter of a power function used } \\
\text { to establish a relation between mois- } \\
\text { ture and the } C_{1} \text { factor }\end{array}$ \\
\hline$n[-]$ & measure of the pore size distribution \\
\hline$P[\mathrm{~m} / \mathrm{s}]$ & precipitation intensity \\
\hline$R_{n}\left[\mathrm{MJ} \mathrm{m}^{-2}\right.$ hour $\left.^{1}\right]$ & net radiation at the grass surface \\
\hline$S_{i}[-]$ & $\begin{array}{l}\text { first order sensitivity index of } i \text {-th } \\
\text { parameter }\end{array}$ \\
\hline$S_{T i}[-]$ & $\begin{array}{l}\text { total sensitivity index of } i \text {-th parame- } \\
\text { ter }\end{array}$ \\
\hline$T_{h r}\left[{ }^{\circ} \mathrm{C}\right]$ & mean hourly air temperature \\
\hline$u_{2}\left[\mathrm{~m} \mathrm{~s}^{-1}\right]$ & average hourly wind speed \\
\hline$w\left[\mathrm{~m}^{3} \mathrm{~m}^{-3}\right]$ & volumetric soil water content \\
\hline$w_{1}\left[\mathrm{~m}^{3} \mathrm{~m}^{-3}\right]$ & $\begin{array}{l}\text { volumetric water content at an upper } \\
\text { layer }\end{array}$ \\
\hline$w_{2}\left[\mathrm{~m}^{3} \mathrm{~m}^{-3}\right]$ & $\begin{array}{l}\text { volumetric water content at a lower } \\
\text { layer }\end{array}$ \\
\hline$w_{\max }\left[\mathrm{m}^{3} \mathrm{~m}^{-3}\right]$ & soil field capacity \\
\hline$\Delta\left[\mathrm{kPa}^{\circ} \mathrm{C}^{-1}\right]$ & slope of vapour pressure curve \\
\hline$\mu[-]$ & $\begin{array}{l}\text { constant used to describe the mois- } \\
\text { ture transport below a lower layer }\end{array}$ \\
\hline$\tau[\mathrm{s}]$ & diurnal time period \\
\hline$w_{r}\left[\mathrm{~m}^{3} \mathrm{~m}^{-3}\right]$ & residual water content \\
\hline$w_{s}\left[\mathrm{~m}^{3} \mathrm{~m}^{-3}\right]$ & saturated water content \\
\hline$\alpha\left[\mathrm{cm}^{-1}\right]$ & $\begin{array}{l}\text { fitting parameter in the } \\
\text { van Genuchten equation }\end{array}$ \\
\hline$\gamma\left[\mathrm{kPa}^{\circ} \mathrm{C}^{-1}\right]$ & psychrometric constant \\
\hline$\rho_{b}\left[\mathrm{~kg} \mathrm{~m}^{-3}\right]$ & soil bulk density \\
\hline$K\left[\mathrm{~m} \mathrm{hr} \mathrm{s}^{-1} \mathrm{~mm}^{-1}\right]$ & unit conversion factor $\left(3.6 \cdot 10^{5}\right)^{-1}$ \\
\hline
\end{tabular}

Received 8 November 2014 Accepted 5 November 2015 